\title{
BMJ Open Impact of COVID-19 pandemic on TB prevention and care in Addis Ababa, Ethiopia: a retrospective database study
}

\author{
Balew Arega (1) , ${ }^{1}$ Abebe Negesso, ${ }^{2}$ Betelhem Taye, ${ }^{2}$ Getachew Weldeyohhans, ${ }^{1}$ \\ Bekure Bewket (D , ${ }^{1}$ Tesfaye Negussie, ${ }^{1}$ Ayele Teshome, ${ }^{1}$ Getabalew Endazenew ${ }^{1}$
}

To cite: Arega B, Negesso A, Taye B, et al. Impact of COVID-19 pandemic on TB prevention and care in Addis Ababa, Ethiopia: a retrospective database study. BMJ Open 2022;12:e053290. doi:10.1136/ bmjopen-2021-053290

- Prepublication history for this paper is available online. To view these files, please visit the journal online (http://dx.doi. org/10.1136/bmjopen-2021053290).

Received 10 May 2021 Accepted 15 January 2022

Check for updates

(C) Author(s) (or their employer(s)) 2022. Re-use permitted under CC BY-NC. No commercial re-use. See rights and permissions. Published by BMJ.

${ }^{1}$ Yekatit 12 Hospital Medical College, Addis Ababa, Ethiopia ${ }^{2}$ Addis Ababa City Administration Health Bureau, Addis Ababa, Ethiopia

Correspondence to

Dr Balew Arega

balewmlt@gmail.com

\section{ABSTRACT}

Objective The current COVID-19 pandemic in Ethiopia could cause severe dysfunction in tuberculosis (TB) treatment, diagnostic services, and prevention and control efforts. In this study, we evaluated the effect of COVID-19 on TB service indicators in Addis Ababa, where more than two-thirds of the country's COVID-19 morbidity was recorded.

Design We performed a comparative retrospective study to evaluate the impact of COVID-19 on TB services during the pre-COVID-19 era (from April 2019 to March 2020) and the COVID-19 era (from April 2020 to March 2021) in Addis Ababa, Ethiopia. We extracted data on total TB detection rate, TB treatment success rate, isoniazid prophylaxis therapy, and drug susceptibility tests and others from the health information system. Using Poisson regression, we estimated the incidence rate ratios and the absolute number difference of the indicators (number per quarter and year) in the COVID-19 and pre-COVID-19 eras.

Results Compared with the pre-COVID-19 era, the total TB detection, bacteriologically confirmed TB, TB treatment success rate, latent TB infection treatment and community health workers' engagement in TB detection decreased, respectively, by $11 \%, 11.8 \%, 17 \%, 44.7 \%$ and $77.2 \%$ during the COVID-19 period. Rifampicin resistance increased by $27.7 \%$ during the same period. Comparative analysis showed a significant decline in these TB service indicators $(p<0.001)$

Conclusion The COVID-19 pandemic has had a negative impact on TB service indicators in Addis Ababa. This highlights the importance of reinforcing TB services, including adopting alternative digital health technology to screen for TB and integrating TB and COVID-19 services to mitigate COVID-19's challenges to TB prevention and care.

\section{BACKGROUND}

The current SARS-CoV-2 2019 pandemic (also known as COVID-19) is causing substantial disruptions in tuberculosis (TB) control and prevention. ${ }^{1}$ Between 2020 and 2025, it is expected to result in an additional 6 million TB cases and 1.4 million TB-related deaths. ${ }^{2}$ Due to lockdowns or movement restrictions, fear of contracting COVID-19 infection in hospital settings and diversion of TB services, patients with TB symptoms are having difficulty accessing healthcare facilities during

\section{Strengths and limitations of this study}

This is the first study investigating the impact of the COVID-19 pandemic on basic tuberculosis (TB) indicators in the epicentre of the pandemic in Ethiopia.

- Data collection occurred 1 year before and 1 year during the COVID-19 era.

- TB service indicator measurements and definitions have been presented based on the national TB guideline.

- We have not collected patient-level data so we cannot assess what happens to individual patients.

this epidemic. ${ }^{3}$ Furthermore, public and government media and health professionals are all focused on COVID-19, while other endemic diseases like TB have gotten less attention. ${ }^{4}$ On the other hand, these factors contribute to longer diagnostic delays, poor treatment outcomes and drug-resistant (DR) TB, increasing the spread of TB in the present and future. ${ }^{4}$ In low-income countries like Ethiopia, where the diagnostic capability of TB cases is suboptimal and there are many undiagnosed TB cases in the community, these issues are predicted to intensify. ${ }^{56}$

Ethiopia is one of the 30 countries with a high TB burden and the disease is the country's leading cause of death. ${ }^{7}$ Ethiopia's government is now implementing the global End TB Campaign, which aims to eradicate TB by 2035 . This has been accomplished through vigorous TB screening, early diagnosis, appropriate treatment and universal drug sensitivity test (DST) at least for rifampicin. ${ }^{8}$ The present COVID-19 situation in Ethiopia, on the other hand, posed a severe barrier to its implementation and slowed progress towards the completion of TB strategy milestones and targets. ${ }^{9}$ The first case of COVID-19 was recorded in Ethiopia on 13 March 2020 and the virus has infected 227255 persons out of 2437495 samples tested (positivity $9.32 \%$ ), resulting in 3146 deaths (as of 
11 April 2021). The number is increasing at an alarming rate, with roughly three-quarters of the cases occurring in and around Addis Ababa. ${ }^{10}$

Essential COVID-19 control and prevention measures, such as mandatory quarantine periods for all travellers, limits on public gatherings, school closures, mandatory face masks in public areas and fewer passengers using public transportation, are on the other hand either modified or lifted. ${ }^{11} 12$ Previously performed studies in the city revealed that during the COVID-19 period, the number of patients presenting with signs and symptoms of TB decreased significantly. ${ }^{13}$ However, the impact of COVID-19 on TB service indicators was not investigated in the study. As a result, we used secondary data obtained from all health facilities in Addis Ababa (the COVID-19 epicentre) to evaluate the impact of the COVID-19 pandemic on selected TB service indicators. These are crucial for determining the possible influence of COVID-19 on TB and developing prevention strategies based on it.

\section{METHODS}

\section{Study design}

Using health management information system (HMIS) data, we conducted a comparative retrospective analysis to assess the impact of COVID-19 on TB service indicators before and during the epidemic.

\section{Study setting}

The research was carried out in Ethiopia's capital, Addis Ababa. The city has a population of 4794000 people, according to the most recent projection (2020). ${ }^{14}$ It has 7 public hospitals and 100 public health centres, which are divided into three categories: health centres, general hospitals and specialist hospitals, in this order. Except for children under the age of 5 , pregnant women, and patients with HIV and TB, who are covered by the free healthcare policy, this network of public health institutions provides services throughout the city on a pay-perservice basis. All health facilities at each healthcare level provide TB care with the assistance of various national special TB initiatives, such as the Millennium Development Goals (target 6) and the recently launched End TB programme. Every quarter, every health facility reports TB cases to the city's administrative health bureau using a nationally standardised and structured reporting form.

\section{Data source and variables}

Between April 2019 and March 2021, we used data from the Addis Ababa health bureau's HMIS. It extracted data from routine service and administrative records, and the indicators are based on the Plan for Accelerated and Sustained Development to End Poverty's priorities, local governments' needs and priorities, and international agreements like the Millennium Development Goals. We divided the data into two study periods: the COVID-19 era (from April 2020 to March 2021) and the pre-COVID-19
Table 1 Operational definition of outcome variables ${ }^{30}$

\begin{tabular}{|c|c|}
\hline Indicators & Definition \\
\hline $\begin{array}{l}\text { TB case detection } \\
\text { rate }\end{array}$ & $\begin{array}{l}\text { Proportion of all forms of TB (new } \\
\text { and relapse) cases detected during a } \\
\text { specified period. }\end{array}$ \\
\hline $\begin{array}{l}\text { Treatment success } \\
\text { rate among drug } \\
\text { susceptibility }\end{array}$ & $\begin{array}{l}\text { Proportion of new TB cases } \\
\text { registered during a specific cohort } \\
\text { period who completed treatment. }\end{array}$ \\
\hline $\begin{array}{l}\text { TB case detection } \\
\text { through community } \\
\text { TB care }\end{array}$ & $\begin{array}{l}\text { Proportion of TB cases detection } \\
\text { contributed by the community out } \\
\text { of all TB cases identified during the } \\
\text { reporting period. }\end{array}$ \\
\hline $\begin{array}{l}\text { Contact screening } \\
\text { coverage (<15 years) }\end{array}$ & $\begin{array}{l}\text { Percentage of screened children } \\
\text { under } 15 \text { years among those with } \\
\text { contact with PTB index cases. }\end{array}$ \\
\hline $\begin{array}{l}\text { LTBI treatment } \\
\text { coverage for children } \\
\text { under } 15 \text { years }\end{array}$ & $\begin{array}{l}\text { Proportion of children aged }<15 \text { years } \\
\text { who have a history of contact with } \\
\text { pulmonary TB cases started on LTBI } \\
\text { treatment. }\end{array}$ \\
\hline $\begin{array}{l}\text { Proportion of } \\
\text { presumptive DR-TB } \\
\text { cases with results for } \\
\text { DST }\end{array}$ & $\begin{array}{l}\text { Percentage of pulmonary TB } \\
\text { (new and retreatment) cases and } \\
\text { presumptive DR-TB cases with } \\
\text { documented DST results during the } \\
\text { reporting period. }\end{array}$ \\
\hline $\begin{array}{l}\text { Number of rifampicin- } \\
\text { resistant MTB cases } \\
\text { detected }\end{array}$ & $\begin{array}{l}\text { Number of DR-TB cases detected } \\
\text { during the reporting period. }\end{array}$ \\
\hline
\end{tabular}

DR-TB, drug-resistant tuberculosis; DST, drug susceptibility test; LTBI, latent tuberculosis infection; MTB, Mycobacterium tuberculosis; PTB, Pulmonary Tuberculosis; TB, tuberculosis.

era (from April 2019 to March 2020). The information was gathered using national HMIS indicators for TB services that are reported every quarter. We extracted data on a year of study (months), total TB detection rate (including relapse), retreatment rate, TB treatment success rate (both clinically and bacteriologically diagnosed), children under the age of 15 contact screening, isoniazid prophylaxis therapy (IPT) for eligible children under the age of 15, TB DST and rifampicin resistance level. Each parameter's definition and computation are presented in table 1 .

\section{Data variables, data sources and data collection}

After data were obtained, Stata (V.16) was used to analyse the data. To calculate the proportion of each indicator, a descriptive analysis was used. Between periods, we compared each of the selected indicators on a quarterly and yearly basis (COVID-19 era and pre-COVID-19 era). To determine the rate ratios comparing registrations per study period in the COVID-19 era with the pre-COVID-19 era, adjusted for year and quarter, Poisson regression was used. The $95 \%$ CI and the level of significance are set at $5 \%$ and at $\mathrm{p}<0.05$.

Patient and public involvement

No patients were involved. 


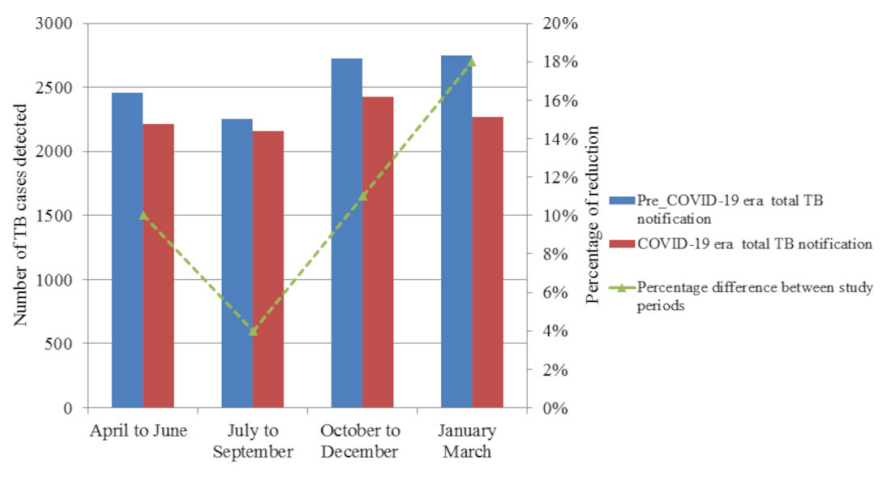

Study periods

Figure 1 Number of patients with tuberculosis (TB) who were notified pre-COVID-19 and during the COVID-19 era in health facilities in Addis Ababa between April 2019 and March 2021.

\section{RESULTS}

\section{Total TB notification}

We reviewed data from the HMIS for 24 months (12 months each during the pre-COVID-19 and COVID-19 eras) for this study. During these time periods, we found a total of 19259 registered new TB cases. Of these, 10187 $(52.9 \%)$ and $9072(47.1 \%)$ were reported during the preCOVID-19 and COVID-19 eras, respectively.

\section{Total TB detection rate trends}

Figure 1 depicts the number of new patients with TB reported per quarter during the pre-COVID-19 and COVID-19 eras. During the quarters of the COVID-19 era, the detection rate of all forms of TB reduced by $4 \%-18 \%$. There was an $11 \%$ decline in total TB notification during the COVID-19 era compared with the pre-COVID-19 era.

\section{TB treatment success}

Overall TB treatment success was recorded in $78.9 \%$ of cases (15 213 of 19259 ) over the study period. When compared with the pre-COVID-19 era, treatment success reduced by $17 \%(\mathrm{p}=0.001)$.

\section{Types of TB diagnosis}

Of a total of 7196 bacteriologically confirmed TB cases, $3824(53.1 \%)$ occurred in the pre-COVID-19 era and the remaining 3372 (46.9\%) occurred in the COVID-19 era. Likewise, out of a total of 12063 clinically diagnosed cases, $6363(52.7 \%)$ occurred in the pre-COVID-19 era and $5700(47.3 \%)$ occurred in the COVID-19 era. The overall number of bacteriologically confirmed TB cases decreased by $11.8 \%$ during the COVID-19 era ( $\mathrm{p}=0.001)$. Figure 2 shows the number of bacteriologically confirmed TB cases decreasing by a quarter during the COVID-19 era.

\section{TB case detection through community TB care}

Community health workers (CHWs) detected only $1.90 \%$ (366 of 19 250) of the total TB cases. The number of community-based TB detections reduced by $77.2 \%$ ( $p=0.001)$ during the COVID-19 era as compared with the pre-COVID-19 era.

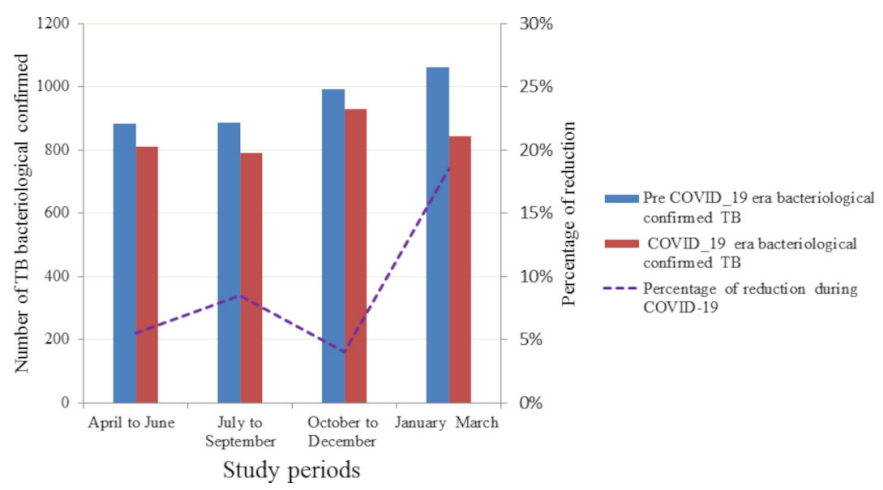

Figure 2 Bacteriologically confirmed tuberculosis (TB) cases pre-COVID-19 and during the COVID-19 era in health facilities in Addis Ababa between April 2019 and March 2021.

\section{TB contact screening and IPT provision}

During the study period, a total of 2588 children under the age of 15 had TB contact and were screened for TB. Of these, 1209 (46.7\%) were pre-COVID-19, while 1379 (53.3\%) were during COVID-19 ( $\mathrm{p}=0.49)$. In the COVID-19 era, compared with the counterpart, the rate of IPT provision per quarter among screened TB contacts of children under 15 years old reduced from $1 \%$ to $57 \%$ (figure 3). During the COVID-19 era, overall IPT provision declined by $44.7 \%$ and the difference was significant $(\mathrm{p}=0.02)$ (table 2).

\section{Drug susceptibility testing and rifampicin resistance}

For $55.14 \%$ (2317 of 4202) of patients with presumptive multidrug resistant TB (MDR-TB), a DST was performed and the DST test performance did not change between the pre-COVID-19 and COVID-19 eras $(\mathrm{p}=0.29)$. More than half (129 of 230) of the 230 rifampicin-resistant (RR) Mycobacterium tuberculosis (MTB) detected during the study period were found during the COVID-19 era, with the remaining $43.9 \%$ (101 of 230) detected during the pre-COVID-19 era (figure 4). The absolute RR-MTB notification rate increased by $27.7 \%(\mathrm{P}=0.001)$ during the COVID-19 era.

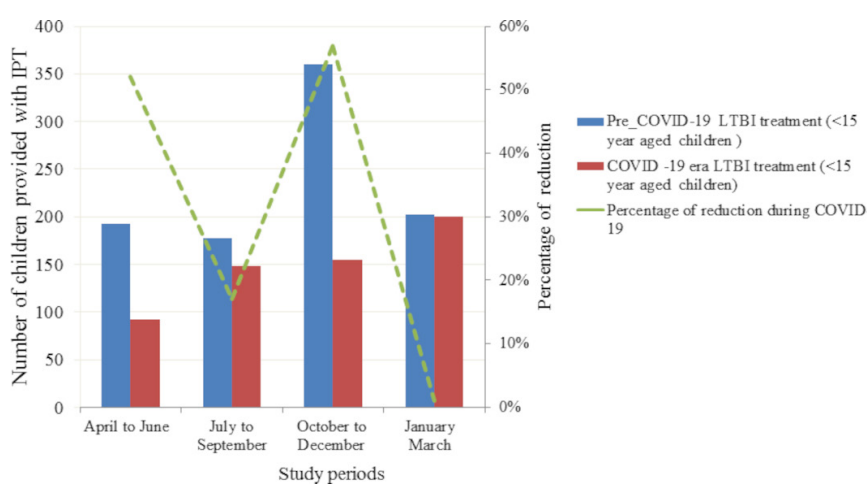

Figure 3 IPT provision among children under $<15$ years who had Pulmonary Tuberculosis contact in health facilities before and during the COVID-19 pandemic in Addis Ababa between April 2019 and March 2021. IPT, isoniazid prophylaxis therapy; LTBI, latent tuberculosis infection. 
Table 2 TB service indicator difference between pre-COVID-19 and COVID-19 eras in Addis Ababa from April 2019 and March 2021

\begin{tabular}{|c|c|c|c|c|}
\hline \multirow[b]{2}{*}{ TB service indicators } & \multicolumn{2}{|l|}{ Period } & \multirow[t]{2}{*}{ AOR $(95 \% \mathrm{Cl})$} & \multirow[t]{2}{*}{ P value } \\
\hline & $\begin{array}{l}\text { COVID-19 } \\
\text { era } \%(N)\end{array}$ & $\begin{array}{l}\text { Pre-COVID-19 era } \\
\%(\mathrm{~N})\end{array}$ & & \\
\hline TB case detection by community TB care, & $0.75(68 / 9072)$ & $2.93(298 / 10187)$ & 0.26 (0.19 to 0.33$)$ & $0.001^{*}$ \\
\hline Contact screening coverage in children under 15 years, & $94.1(1297 / 1379)$ & $96.7(1169 / 1209)$ & 0.97 (0.89 to 1.05$)$ & 0.49 \\
\hline Rifampicin/MDR resistance TB cases detected, & $11.9(129 / 1083)$ & $8.2(101 / 1234)$ & $1.5(1.12$ to 1.91$)$ & $0.004^{*}$ \\
\hline
\end{tabular}

*Significantly associated.

AOR, Adjusted Odd Retio.; DST, drug sensitivity test; LTBI, latent tuberculosis infection; MDR, Multidrug resistant; TB, tuberculosis.

\section{DISCUSSION}

The COVID-19 pandemic threatens to reverse recent progress in reducing the worldwide burden of TB disease, and novel ways to ensure the continuity of TB care during the COVID-19 pandemic are urgently needed. During the COVID-19 era, we identified a substantial decrease in overall TB detection, TB treatment success, community TB case detection, latent TB IPT provision among children under 15 years of age and an increased rate of RR-MTB.

The total TB detection rate in our study throughout the COVID-19 period (April 2020-March 2021) was shown to be significantly lower (11\%). In other studies, in African countries, TB notification rates have decreased by $43 \%$ in Uganda, ${ }^{15} 34 \%$ in Nigeria ${ }^{16}$ and $33 \%$ in South Africa ${ }^{17}$ during the pandemic.

This could be attributed to reorganisation of hospitals and health centres for COVID-19 care and isolation, patients' fear of contracting COVID-19 in health facilities, and reallocation of healthcare professionals for COVID-19 care and other measures. However, the lower rate of $\mathrm{TB}$ detection reduction in our study compared with the previously stated research could be attributed to

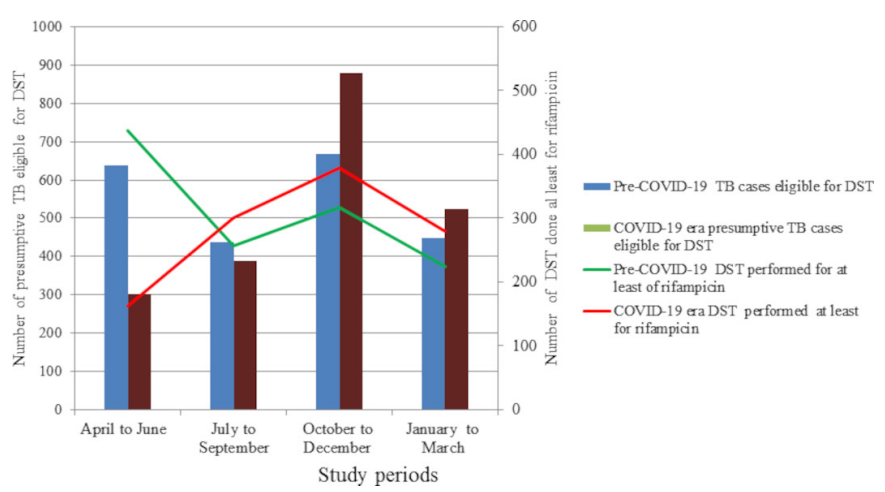

Figure 4 Drug susceptibility was performed at least for rifampicin and the level of rifampicin resistance in health facilities before and during COVID-19 pandemic in Addis Ababa between April 219 and March 2021. DST, drug sensitivity test; TB, tuberculosis. differences in our country's COVID-19 control methods. Ethiopia was taken over for a short period banning of large meetings, and schools and colleges were closed, public transportation restricted, sporting and religious gatherings halted, and quarantine and isolation imposed. ${ }^{18}$ In addition, some of the studies listed collected short-term data, ${ }^{1617}$ while others attempted to explore the effect of a specific public policy such as lockdowns on TB notification. ${ }^{15}$ A model analysis supports our conclusions by assuming that TB incidence in 2020 maintains its modest fall from recent years and that COVID-19 pandemic does not have a substantial impact on $\mathrm{TB}$ trends in the short term. ${ }^{19}$ The fall in TB notification rates seen does not necessarily indicate a decrease in incidence, but could indicate underdiagnoses. Due to missed diagnoses, a significant decrease in $\mathrm{TB}$ case detection has resulted in a build-up of undetected TB, leading to ongoing TB transmission and greater rates of latent TB infection. As a result, using virtual care and digital health technology, as well as assisting CHWs and private health sectors, and merging COVID-19 and TB screening may be the best way to mitigate the pandemic's impact on TB services.

Ethiopia has been using direct observed therapy (DOT) to treat TB for more than a decade and has a track record of effectiveness. ${ }^{20}$ Patients in this programme are expected to visit DOT centres every day, especially during the first 4 months of a 6-month TB treatment cycle. However, such health facility-dependent services are predicted to be impacted during pandemics, whether due to the economic burden, movement restrictions or the disease's stigma. ${ }^{21}$ The success rate of TB therapy declined from $82.4 \%$ in the pre-COVID-19 period to $77.6 \%$ during the COVID-19 pandemic, according to the current study. This is in line with a Korean study that found the treatment success rate had dropped from $89.4 \%$ to $84.5 \% .^{22}$ Reduced TB treatment success raises the probability of poor treatment results and the development of DR-TB, aggravating the country's ongoing DR-TB problem.

In Ethiopia, national TB programmes have traditionally focused on increasing access to effective TB treatment 
through government health institutions. Since 2003, however, the National Tuberculosis Programs (NTPshave increased their use of CHWs, health extension workers and community volunteers to provide effective TB care. ${ }^{23}$ They are in charge of finding patients with suspected TB and reporting them to health centres for diagnosis, as well as providing treatment support, tracing those who have gone missing and conducting contact investigations. ${ }^{24}$ However, in our research, CHWs detected less than 2\% of the total patients with $\mathrm{TB}$, and the detection rate was significantly lower during the COVID-19 era.

The TB elimination strategy and the completion of the TB programme in Ethiopia include contact screening of people living with HIV and children under the age of 5 (now 15) who are contacts of patients with TB. According to $\mathrm{WHO} /$ Center for disease control and prevention (CDC) and a recent meta-analysis, IPT is effective for 93\% of children under the age of 5 and for $59 \%$ aged 15 years or younger. ${ }^{2526}$ In this study, IPT was given to less than twothirds of children aged 15 and under who had contact with symptomatic patients with Pulmonary Tuberculosis(PTB). When compared with the pre-COVID-19 era (79.8\%), provision is much lower during the COVID-19 era (37.7\%). This is in line with comparable research undertaken in Ethiopia (6\%) and South Africa prior to the COVID-19 era $(68 \%) .{ }^{27} 28$ This study's much decreased IPT provision during COVID-19 could be due to stigma and fear of COVID-19 infection at healthcare institutions, which may deter patients from seeking TB treatment. This is because existing national contact tracing depends heavily on passive child contact screening, in which parents are asked to bring their children to a health facility. In this study, however, the reduced level of IPT provision combined with a high level of contact screening (95\%) resulted in lost opportunities for IPT in at-risk children. These discrepancies may imply that healthcare providers should have the information, skills and instruments to counsel parents or caregivers about the significance of preventative treatment, even for otherwise healthy children.

There were no significant variations in the rate of drug susceptibility tests before and after the COVID-19 pandemic, and approximately half of the bacteriologically proven $\mathrm{TB}$ cases were tested at least for rifampicin, according to the findings. Similarly, $61 \%$ of persons with bacteriologically proven TB were tested for rifampicin resistance in 2019 , compared with $51 \%$ in $2017 .{ }^{29}$ The detection of RR-MTB rose by $27.7 \%$ during the COVID-19 era compared with the pre-COVID-19 era in this investigation. As a result, we might assume that the rising number of RR-MTB cases and lower treatment success rates in the study environment are due to a continuous increase in MDR and a larger level of DR-TB. This is expected to result in community-wide drug resistance dissemination at a critical time when Ethiopia's persistent TB control efforts have resulted in a major reduction in TB burden over the last two decades.

The current study did not look at the possibility of direct interactions between TB and COVID-19. Individual sociodemographic variables and public health preventative measures on $\mathrm{TB}$ service indicators and trends were determined using aggregated data gathered quarterly. The study solely looked at the TB cascade's trend and did not employ qualitative methods to look at potential factors of the lowering trend.

\section{CONCLUSION}

COVID-19 had a detrimental influence on fundamental TB service indicators, such as detection, treatment success, community participation, IPT provision and exaggerated RR-TB/MDR-TB in the previous year, according to the findings of this study. To meet these challenges, the TB programme must quickly adapt to the new normal by strengthening the patient-centred approach to TB care, embracing digital health technology, raising awareness, strengthening community-based active TB case finding and integrating the COVID-19 and TB screening service. The COVID-19 service can be used to address the community and screen for $\mathrm{TB}$, such as during vaccination, especially in high-risk communities. By strengthening existing programmes and implementing new ones, our country will be able to maintain the advances made during the last decade to combat $\mathrm{TB}$ and the control programmes and to achieve the End TB programme goals.

Acknowledgements We would like to thank the Addis Ababa City Administrative Health Bureau HMIS unit workers for their cooperation during data extraction.

Contributors BA and AN contributed to the design of the study; collected, entered, analysed and interpreted the data; and prepared the paper. BA is guarantor. BT and GW contributed to the conception and design of the study, collected, and drafted the paper. BB, TN and AT contributed to the interpretation and data analysis and review of the results. GE contributed to the interpretation of the results and to drafting and critical review of the paper. All authors read and approved the final paper.

Funding The authors have not declared a specific grant for this research from any funding agency in the public, commercial or not-for-profit sectors.

Competing interests None declared.

Patient and public involvement Patients and/or the public were not involved in the design, or conduct, or reporting, or dissemination plans of this research.

Patient consent for publication Not required.

Ethics approval We obtained ethical approval from the Y12HMC Ethical Committee. The institutional review board waived the need for written informed consent from participants since the study required no direct contact with human subjects (no interview or sample collection) and only used pooled programme/ health information system.

Provenance and peer review Not commissioned; externally peer reviewed.

Data availability statement All data relevant to the study are included in the article or uploaded as supplementary information. All data relevant to the study are included in the article

Open access This is an open access article distributed in accordance with the Creative Commons Attribution Non Commercial (CC BY-NC 4.0) license, which permits others to distribute, remix, adapt, build upon this work non-commercially, and license their derivative works on different terms, provided the original work is properly cited, appropriate credit is given, any changes made indicated, and the use is non-commercial. See: http://creativecommons.org/licenses/by-nc/4.0/.

\section{ORCID iDs}

Balew Arega http://orcid.org/0000-0002-4222-8420

Bekure Bewket http://orcid.org/0000-0002-8374-2477 


\section{REFERENCES}

1 WHO. Global tuberculosis report, 2020.

2 Stop TB Partnership. The potential impact of the covid-19 response on tuberculosis in high-burden countries: a modeling analysis. Available: http://www.stoptb.org/assets/documents/news/

3 World Health Organization. Information note: tuberculosis and COVID-19, 2020.

4 Togun T, Kampmann B, Stoker NG, et al. Anticipating the impact of the COVID-19 pandemic on TB patients and TB control programmes. Ann Clin Microbiol Antimicrob 2020;19:21.

5 Buonsenso D, lodice F, Sorba Biala J, et al. COVID-19 effects on tuberculosis care in Sierra Leone. Pulmonology 2021;27:67-9.

6 Saunders MJ, Evans CA. COVID-19, tuberculosis and poverty: preventing a perfect storm. Eur Respir J 2020;56:2001348.

7 Ethiopia Federal Ministry of Health. Guideline for program and clinical management of drug-resistant tuberculosis. 5th edn. Addis Ababa: $\mathrm{FMOH}, 2009$

8 Haileamlak A. Ethiopia is on track of achieving the who end tuberculosis milestone. Ethiop J Health Sci 2021;31:1-2

9 Mohammed H, Oljira L, Roba KT, et al. Containment of COVID-19 in Ethiopia and implications for tuberculosis care and research. Infect Dis Poverty 2020;9:131.

10 Alene KA, Gelaw YA, Fetene DM, et al. COVID-19 in Ethiopia: a geospatial analysis of vulnerability to infection, case severity and death. BMJ Open 2021:11:e044606.

11 WHO. WHO Ethiopia COVID-19 situation report. Available: https:// covid19.who.int/region/afro/country/et [Accessed 11 April 2020].

12 Shewamene Z, Shiferie F, Girma E, et al. Growing ignorance of COVID-19 preventive measures in Ethiopia: experts' perspective on the need of effective health communication strategies. Ethiop $J$ Health Sci 2021;31:201-4.

13 Beyene NW, Sitotaw AL, Tegegn B, et al. The impact of COVID-19 on the tuberculosis control activities in Addis Ababa. Pan Afr Med J 2021;38:243.

14 Addis Ababa, Ethiopia Metro area population 1950-2021. Available: htts://www.macrotrends.net/cities/20921/addis-ababa/population

15 Kadota JL, Reza TF, Nalugwa T, et al. Impact of shelter-in-place on TB case notifications and mortality during the COVID-19 pandemic. Int J Tuberc Lung Dis 2020;24:1212-4.
16 Adewole OO. Impact of COVID-19 on TB care: experiences of a treatment centre in Nigeria. Int J Tuberc Lung Dis 2020;24:ijt Id.20.0418:981-2.

17 National Institute for Communicable Diseases. Impact of COVID-19 intervention on TB testing in South Africa 2020.

18 Ministry of Health Ethiopia. National comprehensive COVID19 management handbook, 2020. https://extranet.who.int/goarn/ national-comprehensive-covid19-management-handbook

19 Cilloni L, Fu H, Vesga JF, et al. The potential impact of the COVID-19 pandemic on the tuberculosis epidemic a modelling analysis. E Clin Med 2020;28:100603.

20 Federal Ministry of Health Ethiopia. Tuberculosis, leprosy and TB/HIV prevention and control programme, 2017.

21 Visca D, Tiberi S, Pontali E, et al. Tuberculosis in the time of COVID-19: quality of life and digital innovation. Eur Respir J 2020;56:2001998.

22 Youn S. Korea TB treatment success rate falls temporarily after Covid-19. Korea Biomed review 2020;11:44.

23 AssefaY G, Y.A Hill, P.S, et al. Community health extension program of Ethiopia, 2003-2018: successes and challenges toward universal coverage for primary healthcare services. Global Health 2019;15:2-11.

24 KhatriU DN. Quality of tuberculosis services assessment in Ethiopia: report. Chapel Hill, NC: MEASURE Evaluation, University of North Carolina, 2020.

25 Yimer S, Holm-Hansen C, Yimaldu T, et al. Evaluating an active case-finding strategy to identify smear-positive tuberculosis in rural Ethiopia. Int J Tuberc Lung Dis 2009;13:1399-404.

26 World Health Organization Stop TB Partnership Childhood TB Subgroup. Childhood contact screening, and management. Int $J$ Tuber Lung Dis 2007;11:12-15.

27 Ayieko J, Abuogi L, Simchowitz B, et al. Efficacy of isoniazid prophylactic therapy in prevention of tuberculosis in children: a metaanalysis. BMC Infect Dis 2014;14:91.

28 Tadesse Y, Gebre N, Daba S, et al. Uptake of isoniazid preventive therapy among under-five children: TB contact investigation as an entry point. PLoS One 2016;11:e0155525.

29 WHO. Global tuberculosis report, 2019.

30 Ministry of Health. HMIS indicator definitions (Ethiopia), 2014. 